\section{Hypoglycaemia in Infancy and Childhood}

Hypoglycaemia in the newborn period and childhood is a relatively common diagnostic and therapeutic emergency. A rapidly growing organ such as the brain of an infant and young child is particularly vulnerable to a low blood sugar, and neonatal hypoglycaemia may cause fits or permanent intellectual impairment. Specific histological changes have been described in the brain of hypoglycaemic newborn babies. ${ }^{1}$ Hypoglycaemia in the newborn is best considered separately from that condition in the older infant and child, because the aetiology and symptoms are different.

The following groups of newborn babies have an increased risk of hypoglycaemia: those with a low birth weight (especially the small-for-dates baby); the smaller of twins; and infants born of mothers with diabetes, particularly those being treated with sulphonylurea drugs. Other conditions associated with an increased risk are maternal toxaemia, respiratory distress syndrome, haemolytic disease, and severe sepsis. Early feeding of premature babies has reduced the severity of hypoglycaemia in that group.

Neonatal hypoglycaemia may be asymptomatic or symptomatic. The symptoms are varied and may be caused by many different conditions. They include convulsions, cyanotic or apnoeic attacks, irritability, lethargy, respiratory distress, hypothermia, hunger, and poor feeding. More commonly the infant is hyperreactive to auditory and tactile stimuli and has a tremor of large amplitude (the "jittery baby"). As these signs are nonspecific and may be mild and unimportant, they can easily be missed. In fact, abnormal behaviour in a newborn infant may be due to hypoglycaemia, and any infant having cyanotic attacks, periods of apnoea, or convulsions should be sent to hospital immediately.

The levels of blood glucose diagnostic of neonatal hypoglycaemia vary with the status at birth. According to M. Cornblath and R. Schwartz ${ }^{2}$ the following diagnostic criteria of hypoglycaemia should be applied: in the fullterm infant two or more blood glucose values of less than $30 \mathrm{mg} / 100 \mathrm{ml}$; in the low-birth-weight infant (less than $2,500 \mathrm{~g}$ ) a blood glucose value of less than $20 \mathrm{mg} / 100 \mathrm{ml}$; in the older infant and child blood glucose values of less than $40 \mathrm{mg} / 100 \mathrm{ml}$. It is essential that the clinician should be aware of what the laboratory is measuring, as these figures apply to the level of glucose in the blood and not to total reducing substances, for in every $100 \mathrm{ml}$ between 5 and $20 \mathrm{mg}$ of reducing substances may be due to compounds other than glucose. Dextrostix remains a useful bedside screening method of determining blood glucose and can be used in the home or surgery as well as in the nursery or ward.

Controversy exists about the clinical significance of asymptomatic hypoglycaemia, but all babies with it should be treated. The initial treatment should be with intravenous glucose and not hydrocortisone, glucagon, or diazoxide. Opinion differs on the safety or necessity of rapid injections of hypertonic solutions ( $50 \%$ glucose), and some physicians consider that the dangers of osmolal disturbances and local sclerosing effects are too great. A less hypertonic solution $(20 \%$ glucose) is satisfactory for most infants. If the blood glucose cannot be maintained above $50 \mathrm{mg} / 100 \mathrm{ml}$ (as shown by serial determinations), hydrocortisone is given intravenously. Serial monitoring of the blood glucose level is essential, as the treatment of neonatal hypoglycaemia is essenti- ally a titration of infused glucose against the infant's blood glucose level.

There are many causes of hypoglycaemia in the older infant and child. ${ }^{3}$ The low blood sugar may result from increased peripheral utilization of glucose or its defective production in the liver. Increased utilization may be due to an insulinoma, islet cell hyperplasia, or the prediabetic state, while defective production may result from inborn errors of carbohydrate metabolism, endocrine disorders, or druginduced alterations of glucose homoeostasis. The pathogenesis of some childhood hypoglycaemic syndromes such as ketotic hypoglycaemia and leucine-induced hypoglycaemia are incompletely understood. In some of these children no cause for the hypoglycaemia is found, and it is then termed "idiopathic." Fortunately clinical manifestations such as pallor, sweating, and dilated pupils are readily detectable in these older children, though hypoglycaemia without these symptoms and signs may occur in patients with low blood glucose due to adrenomedullary insufficiency. ${ }^{4}$

The most useful initial investigation of a patient with suspected hypoglycaemia is a 24-hour fast while under constant supervision and having frequent measurements of blood glucose. Samples should be obtained to measure the plasma insulin and free fatty acids, and the urine should be tested for ketones. A prolonged fast may be unpleasant for the child, and serial blood glucose results should be readily available or use should be made of Dextrostix to decide on terminating the test if hypoglycaemia occurs. Inability to produce hypoglycaemia by a prolonged fast should discourage further provocation tests. In the event of a positive result (a blood glucose less than $40 \mathrm{mg} / 100 \mathrm{ml}$ ) further specific tests of hepatic and endocrine function and studies of peripheral utilization should be considered. However, some of these tests can be hazardous to the child's life and so should be carried out only in centres where there are experienced staff and adequate laboratory facilities. Even after full investigation it is not always possible to determine the cause of hypoglycaemia.

In summary, neonatal hypoglycaemia requires a high index of suspicion for diagnosis and a sense of urgency in treatment, while hypoglycaemia in the older infant and child requires carefully planned investigation with an awareness of the dangers involved in provocation tests.

1 Anderson, J. M., Milner, R. D. G., and Strich, S. J., Lancet, 1966, 2, 372. Cornblath, M., and Schwartz, R., Disorders of Carbohydrate Metabolism in Infancy. Philadelphia, Saunders, 1966.

${ }^{3}$ Greenberg, R. E., and Christiansen, R. O., Pediatrics, 1970, 46, 915.

4 Broberger, O., and Zetterstrom, R. J., Pediatrics, 1961, 59, 215.

\section{Contraception and Blood Pressure}

Several months ago the risk of hypertension occurring in women taking oral contraceptives was reviewed in these columns. ${ }^{1}$ Since several retrospective surveys had suggested that the incidence of hypertension in women taking these drugs varies greatly, it was thought that two pieces of information were needed for a realistic assessment of the problem. These were a detailed prospective measurement of blood pressure in a group of women known to be normotensive before taking oral contraceptives and secondly measurement of the blood pressure in women already hypertensive before being prescribed an oral contraceptive. Several studies in recent months give some help on both aspects. 
Firstly, R. J. Weir, of the Medical Research Council's Blood Pressure Unit in Glasgow, and colleagues in the Glasgow Clinic of the Family Planning Association ${ }^{2}$ studied levels of blood pressure in 100 women before and during a year's treatment with oral contraceptives and in a control group of 34 women using mechanical forms of contraception. All were normotensive before beginning contraception. Since there is some evidence that oestrogen is the cause of the hypertension, two oral contraceptives with different concentrations of oestrogen were used. Of the 100 women who started 66 were followed up for a year. Reasons for failure to complete the trial included pregnancy (one patient) and adverse publicity about oral contraceptives ( 7 patients). Twenty-one of the 34 patients $\left(62^{\prime}\right)$ using mechanical forms of contraception stayed the course. It was noticeable, and perhaps important, that the women using oral contraceptives were younger than those in the other group, and more were nulliparous.

The first reassuring fact which emerged was that in no patient on oral contraceptives did the blood pressure rise above $140 / 90 \mathrm{~mm} \mathrm{Hg}$. An average rise in systolic pressure of $6.6 \mathrm{~mm} \mathrm{Hg}$ was noted, but there was no significant change in the mean level of the diastolic pressure. Further, there appeared to be no difference between the two contraceptive preparations used in their tendency to produce this rise in systolic pressure. Of particular interest were four women whose systolic blood pressure increased by between 20 and $30 \mathrm{~mm} \mathrm{Hg}$ in 12 months, and further information on this subgroup would be welcome. In the control group there was no significant change in either systolic or diastolic blood pressure. Dr. Weir and his colleagues are to be congratulated on the lengths they went to in order to prevent bias, which has vitiated so many previous studies of this kind.

The second report comes from California and concerns 22 women who were found to be hypertensive while taking oral contraceptives. ${ }^{3}$ The mean blood pressures before, during, and after treatment were $125 / 76,183 / 110$, and $130 / 82$ $\mathrm{mm} \mathrm{Hg}$ respectively. Several of these patients were hypertensive before oral contraception began. The time recorded for high levels of pressure to become evident varied considerably, but in some cases the delay was due to a failure to document blood pressure over long periods. This illustrates one of the problems which the Glasgow study should be in a position to answer-the time relationship between development of hypertension and start of oral contraception. There was also a variation of between 1 and 12 months after stopping oral contraceptives before normal levels of blood pressure were regained.

The third report, from the University of Texas, documents the occurrence of a level of blood pressure above $140 / 90 \mathrm{~mm} \mathrm{Hg}$ in 10 of 56 women given an oral contraceptive and followed up for periods up to 30 weeks. ${ }^{4}$ Of six women with already raised levels of pressure one became normotensive, four remained hypertensive, and in one the hypertension became worse. The authors of this article are, rightly, unwilling to extrapolate their findings to a large group, since there was no proof that in this sample of postpartum woman oral contraceptives were the only possible cause of the hypertension. Secondly, the patients were mainly coloured women, in whom the incidence of essential hypertension is high.

What then are the practical consequences to be considered? If a woman wishes to take oral contraceptives, her blood pressure should be measured first. If she is normotensive, the risk of her blood pressure going up would appear to be small, though not immeasurably small, and it would be wise to check it at regular (say six-monthly) intervals. If she is already hypertensive the position may be different, though there is still little published evidence to suggest any risk of an exacerbation of the hypertension. Here it is hardly possible to say more than that the woman's requirements need to be assessed with exceptional care, attention being paid to all her needs and circumstances.

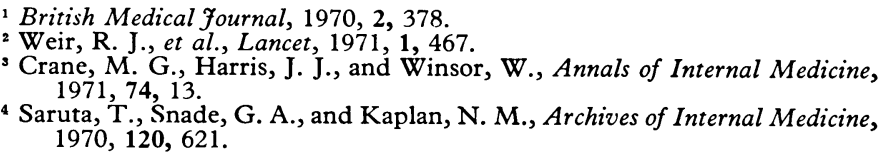

\section{Humane Care}

So battered and bruised is the image of our mental hospitals, and in particular those designed primarily for the care of the mentally handicapped, that any report relating to them is seized upon by the mass media as an opportunity to put the boot in yet again. A further assault came, as might have been predicted, when a recent report ${ }^{1}$ was published. But in this instance the attackers could have conserved their energies for an occasion with more justification than this one affords. The remarkable feature of this report is that it is written without rancour, sensationalism, emotionalism, or holier-than-thou attitudes. This is equally true in a political respect, for Sir Keith Joseph, Secretary of State for the Social Services, points out in his foreword: "This report was commissioned by my predecessor as part of the measures he initiated to improve the lot of the mentally handicapped within the hospital service." "Its purpose," he writes, "was to provide architectural advice on the immediate problems of overcrowding and poor environmental conditions in our existing hospitals for the mentally handicapped."

The study on which the report is based was carried out by a team of architects and planners, quantity surveyors, and engineers under the leadership of Mr. John Weeks, F.R.I.B.A., assisted by medical and nursing advisers from the Department of Health and Social Security. Not unnaturally, they were disturbed by much of what they saw. They noted, more in sorrow than in anger, the lack of privacy or "personal space" in which mentally handicapped people (they insist on the use of "people" rather than "patient" throughout) can dress and undress with propriety and enjoy their personal possessions. They noted too the insufficiency of baths, lavatories, and wash-basins, the poor ventilation of many sanitary annexes, and the high degree of regimentation at meal times, which reinforced the institutional effect.

Even so, they have colours other than black on their palette. They paint in glowing colours the developments and improvements achieved recently in hospitals and other residential places visited during the course of the study. Six projects are chosen, illustrated by plans and photographs of what they term "a good approach to the problems discussed throughout the study." They range from a new 30-bed mixed residential unit on a hospital site to upgraded wards in a large nineteenth century hospital. Tribute too is paid to the ingenuity and ability of some staff in the use of limited resources to give a domestic atmosphere to the rooms. 